\title{
Dodecyl Mercaptan Functionalized Copper Mesh for Water Repellence and Oil-water Separation
}

\author{
Yanling Tian ${ }^{1,2,3}$, Jiekai Feng ${ }^{1,2}$, Zexin Cai ${ }^{1,2}$, Jiaqi Chao ${ }^{1,2}$, Dawei Zhang ${ }^{1,2}$, \\ Yuxiao Cui ${ }^{4}$, Faze Chen ${ }^{1,2^{*}}$ \\ 1. School of Mechanical Engineering, Tianjin University, Tianjin 300072, China \\ 2. Key Laboratory of Mechanism Theory and Equipment Design of Ministry of Education, Tianjin University, Tianjin 300072, China \\ 3. School of Engineering, University of Warwick, Coventry CV4 7DL, UK \\ 4. School of Mechanical Engineering, Tianjin University of Technology and Education, Tianjin 300222, China
}

\begin{abstract}
Reckless discharge of industrial wastewater and domestic sewage as well as frequent leakage of crude oil have caused serious environmental problems and posed severe threat to human survival. Various nature inspired superhy-drophobic surfaces have been successfully applied in oily water remediation. However, further improvements are still urgently needed for practical application in terms of facile synthesis process and long-term durability towards harsh environment. Herein, we propose a simple one-step dodecyl mercaptan functionalization method to fabricate Super-hydrophobic-Superoleophilic Copper Mesh (SSCM). The prepared SSCM possesses excellent water repellence and oil affinity, enabling it to successfully separate various oil-water mixtures with high separation efficiency (e.g., $>99 \%$ for hexadecane-water mixture). The SSCM retains high separating ability when hot water and strong corrosive aqueous solutions are used to simulate oil-water mixtures, indicating remarkable chemical durability of the dodecyl mercaptan functionalized copper mesh. Additionally, the efficiency can be well maintained during 50 cycles of separation, and the water repellence is even stable after storage in air for 120 days, demonstrating the reusability and long-term stability of the SSCM. Furthermore, the functionalized mesh also shows good mechanical robustness towards abrasion by sandpaper, and oil-water separation efficiency of $>96 \%$ can be obtained after 10 cycles of abrasion. The reported one-step dodecyl mercaptan functionalization could be a simple method for increasing the water repellence of copper mesh, and thereby be a great candidate for treating large-scale oily wastewater in harsh environments.
\end{abstract}

Keywords: copper mesh, superhydrophobic, oil-water separation, stability, reusability

Copyright $($ The author(s) 2021.

\section{Introduction}

Frequent occurrence of oil spills, and massive discharge of industrial and domestic oily wastewater make the problem of oil and water pollution increasingly serious, causing great harm to the ecological environment ${ }^{[1-4]}$. How to efficiently treat the oil-water mixture and thus obtain reusable pure water and oil is one of the most attractive scientific problems. Traditional methods for treating water and oil pollution can be broadly divided into three categories: biodegradation ${ }^{[5]}$, chemical treatment ${ }^{[6,7]}$ and physical separation by skimmer and oil absorption felt, etc. ${ }^{[8,9]}$. However, these methods are generally characterized by low separation efficiency, poor oil-water selectivity, low reusability and high cost.

Many plants and animals in nature have special wettability on their surfaces. For example, the self-cleaning function of lotus leaves originate from the superhydrophobicity of their upper surface ${ }^{[10]}$; fish swims in oily water without being contaminated by oil because their scales are superhydrophilic and underwater superoleophobic ${ }^{[11]}$; desert beetles can survive in extreme dry environment due to the superhydrophilic-superhydrophobic patterned surface on their backs facilitates the collection of fog ${ }^{[12]}$. Therefore, in recent years, biomimetic interfaces with special wettability have attracted great attention from both scientific researchers and engineers ${ }^{[13-19]}$. Because of their outstanding liquid repellence or affinity, high separation efficiency and flux, functional surfaces with super wettability have been widely developed for oil-water separation, and these surfaces can be classified as superhydrophobic-superoleophilic surfaces, superhydrophilic-underwater superoleophobic surfaces and con-

\footnotetext{
*Corresponding author: Faze Chen

E-mail: faze.chen@tju.edu.cn
} 
vertible superwetting surfaces ${ }^{[20-27]}$. Typically, oil-water separation can be realized via filtering or adsorption by these surfaces with super wettability. The adsorbent materials are mainly $3 \mathrm{D}$ porous foams ${ }^{[28]}$, sponges $^{[29,30]}$, aerogels ${ }^{[31,32]}$, powders or particles ${ }^{[33]}$, which are suitable for the adsorption and transfer of oil spills on water surface. In contrast, filtering is more desired for the separation of collectible oil-water mixtures, and porous metal mesh ${ }^{[34-36]}$, membranes ${ }^{[37,38] \text {, fiber fabrics }}{ }^{[39,40]}$ and filter papers ${ }^{[41]}$ are always selected as the substrates to create surfaces with super wettability for filtering type separation. Among them, metal meshes (e.g., Copper Mesh (CM)) are characterized with good mechanical strength, cheapness and easy availability, etc. More importantly, due to the high activity of metal meshes, chemical reactions and modifications can be easily performed on their surfaces to construct super wettability. For example, Cheng et al. prepared spherical structures of $\mathrm{Cu}(\mathrm{OH})_{2}$ on $\mathrm{CM}$ and modified them with thiols to obtain superhydrophobic surfaces with controlled adhesion $^{[42]}$. Liu et al. prepared rough $\mathrm{Cu}(\mathrm{OH})_{2}$ nanopins on $\mathrm{CM}$ with tunable wettability to separate mixed-phase solutions ${ }^{[43]}$. Ansah et al. prepared various morphologies of $\mathrm{Cu}(\mathrm{OH})_{2}$ and $\mathrm{CuO}$ on $\mathrm{CM}$, such as needle-shaped, hair-shaped and arch-shaped structures, which were further modified with fluorosilanes to obtain superhydrophobic surfaces ${ }^{[44]}$. However, those universal synthesis methods are relatively complex and environmentally-unfriendly, often requires two steps consisting of building micro-nanostructures and low surface energy material modification, and the direct construction of superhydrophobic surfaces by a one-step method with good durability towards harsh environments (e.g., corrosive aqueous solutions) remains a great challenge $\mathrm{e}^{[45]}$. Therefore, it is of great relevance and urgency to develop a robust superhydrophobic interface with simple preparation process and high environmental adaptability.

Herein, we report a simple and eco-friendly one-step immersion strategy to fabricate $\mathrm{Su}$ per-hydrophobic-Superoleophilic Copper Mesh (SSCM). The self-assembly reaction of copper and dodecyl mercaptan could generate a layer of micro-nanostructures on the surface of the CM and reduce its surface energy, imparting the mesh with superhydrophobicity and superoleophilicity. The whole process can be completed in
$2 \mathrm{~h}$ at room temperature without using any harmful fluorinated chemicals. The effect of different immersion time on the wettability of $\mathrm{CM}$ was investigated via water contact angle measurement. Since the excellent superhydrophobic and superoleophilic properties, the separation efficiency of oil-water mixtures was measured to be $>97 \%$. It was found that the as-prepared SSCM showed excellent separation ability even under hot water, acidic, alkaline and salty conditions. The separation efficiency could be well maintained after 50 separation cycles.

\section{Materials and methods}

\subsection{Materials}

CMs with different size were purchased from Shanghai composite sieve works. The distilled water was provided by a UCP-III water purification system. Sodium chloride $(\mathrm{NaCl})$, sodium hydroxide $(\mathrm{NaOH})$, hydrochloric acid $(\mathrm{HCl})$ and dodecyl mercaptan $\left[\mathrm{CH}_{3}\left(\mathrm{CH}_{2}\right)_{10} \mathrm{CH}_{2} \mathrm{SH}\right]$ were purchased from Shanghai Aladdin Biochemical Technology Co. Hexadecane, peanut oil, hexane, octane for oil-water separation were purchased from Tianjin Yuanli Chemical Co, and dichloromethane was purchased from Tianjin Kosmeo Chemical Reagent Co. All chemicals were AR level and used without further purification.

\subsection{Sample preparation}

Before preparation, the raw $\mathrm{CM}$ was cut into circle samples $(D=5 \mathrm{~cm})$ firstly. The oxide on the $\mathrm{CM}$ surface was removed by immersing $0.1 \mathrm{~mol} \cdot \mathrm{L}^{-1}$ hydrochloric acid solution for $1 \mathrm{~min}$. Then the CMs were ultrasonically washed with ethanol and distilled water in turn, and dried in the air. Finally, the samples were immersed in $0.1 \mathrm{~mol} \cdot \mathrm{L}^{-1}$ dodecyl mercaptan ethanol solution for $2 \mathrm{~h}$ at room temperature. The modified CMs were flushed with anhydrous ethanol and dried in air.

\subsection{Sample characterization}

Static contact angle and sliding angle of water and oil on the prepared samples were measured by an optical contact angle meter (ASTVCM Optima, USA) at room temperature, and the used volume of the droplets were $7 \mu \mathrm{L}$. The contact angle at 5 different positions of the surface were measured and the average value was calculated and reported in this paper. Scanning Electron 
Microscope (SEM, SUPRA 55 SAPPHIRE, Germany) was used to observe the surface morphology of the samples, and the chemical composition of the surface was analyzed by Energy-Dispersive X-ray spectroscopy (EDS, SUPRA 55 SAPPHIRE, Germany) and X-ray Photoelectron Spectroscopy (XPS, Thermo ESCALAB 250Xi, USA).

\subsection{Oil-water separation}

The prepared SSCM was fixed between two identical glass tubes with a clamping device, and the glass tubes were fixed at an inclination angle of $45^{\circ}$. The prepared oil-water mixture was slowly poured into the upper tube and the whole separation process was driven by gravity. The oil-water separation efficiency could be calculated by $\eta(\%)=\left(1-M_{\mathrm{d}} / M_{\mathrm{o}}\right) \times 100 \%$, where $M_{\mathrm{c}}$ and $M_{\mathrm{o}}$ represent the mass of collected oil and the mass of original oil in the oil-water mixture, respectively. The flux of oil $\left(F_{\mathrm{o}}\right)$ during oil-water separation was calculated by $F_{\mathrm{o}}=V / S_{t}$, where $V$ represented the volume of the oil in the mixture, $S$ was the effective cross-sectional area of the SSCM used for oil-water separation, and $t$ was the time required for the oil in the mixture to completely pass through the SSCM. The water was dyed blue for better visual effect. The oils used in the experimental process included hexadecane, peanut oil, hexane, octane and dichloromethane, and their basic parameters are presented in Table S1.

\section{Results and discussion}

\subsection{Formation of superhydrophobicity and wetta- bility}

The preparation process of the SSCM is shown in Fig. 1. When the CM was immersed into dodecyl mercaptan ethanol solution, a direct adsorption chemical reaction occurred on the surface, which was accompanied by oxidative addition to the surface bonds of the $\mathrm{CM}$ and the reduction of hydrogen elimination ${ }^{[46]}$ :

$$
\begin{aligned}
& 2 \mathrm{CH}_{3}\left(\mathrm{CH}_{2}\right)_{10} \mathrm{CH}_{2} \mathrm{SH}+2 \mathrm{Cu} \rightarrow \\
& \quad 2 \mathrm{CH}_{3}\left(\mathrm{CH}_{2}\right)_{10} \mathrm{CH}_{2} \mathrm{SCu}+\mathrm{H}_{2} \uparrow .
\end{aligned}
$$

As a result of the adsorption reaction, self-assembled monolayers were formed on the surface.

The micro/nano structures and the low surface energy of the self-assembled monolayers enabled the CM to be superhydrophobic by this one-step adsorption reaction. Fig. 2a shows the digital image of droplets (water, $1 \mathrm{~mol} \cdot \mathrm{L}^{-1} \mathrm{HCl}, 1 \mathrm{~mol} \cdot \mathrm{L}^{-1} \mathrm{NaOH}$ and $20 \mathrm{wt} \%$ $\mathrm{NaCl}$ ) deposited on the as-prepared superhydrophobic $\mathrm{CM}$, which demonstrated that all the droplets retained as spherical shape, and the corresponding Water Contact Angle (WCA) of the functionalized mesh is about $153^{\circ}$ (Fig. 2b). By contrast, a slowly released hexadecane droplet was observed to spread on the mesh

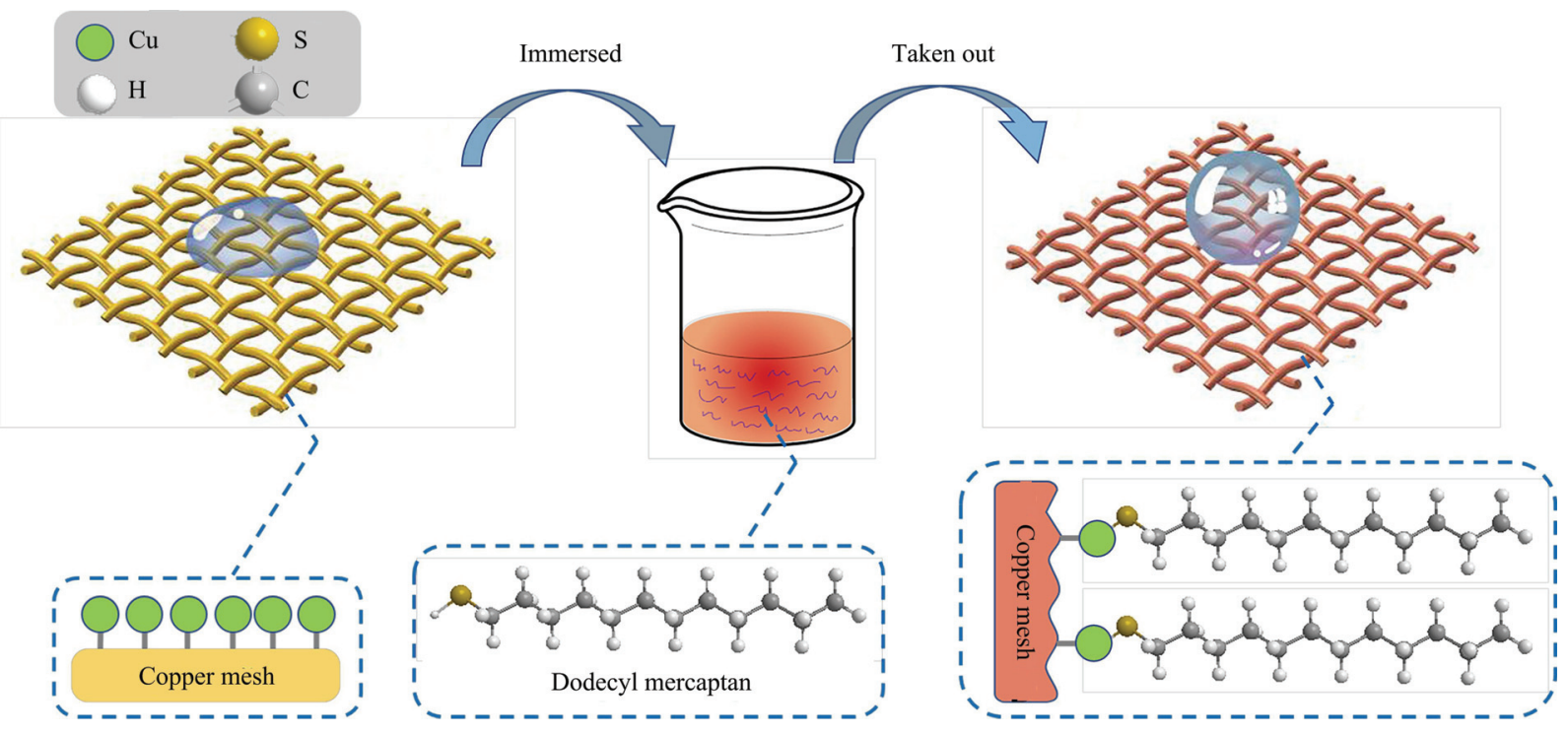

Fig. 1 Schematic illustration of the fabrication process and mechanism of the SSCM. 


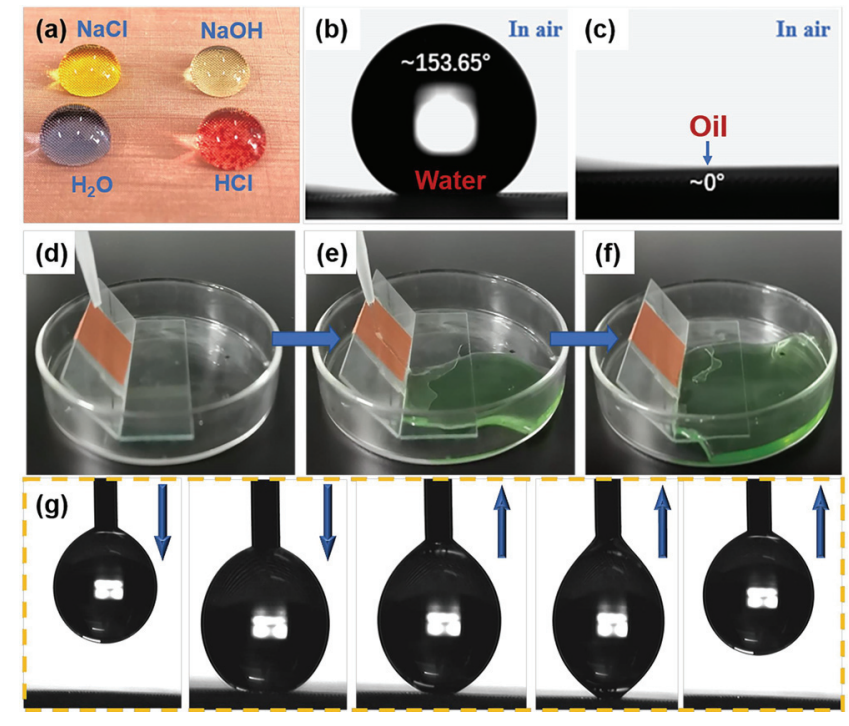

Fig. 2 (a) Digital image showing water, $\mathrm{NaCl}$ (20 wt $\%$ ), $\mathrm{NaOH}$ $\left(1 \mathrm{~mol} \cdot \mathrm{L}^{-1}\right)$ and $\mathrm{HCl}\left(1 \mathrm{~mol} \cdot \mathrm{L}^{-1}\right)$ droplets deposited on the SSCM; $(b, c)$ Water and hexadecane contact angles of the SSCM; $(d-f)$ digital images illustrating water jet impacting on the SSCM; (g) process of a water droplet contacting, pressing and disconnecting with the SSCM. rapidly, and the Oil Contact Angle (OCA) is nearly $0^{\circ}$ (Fig. 2c), indicating that the one-step dodecyl mercaptan functionalization created a SSCM. When a water jet was sprayed onto the surface of the SSCM, the jet bounced and detached from the surface without any residual on the SSCM (Figs. 2d-2f). Furthermore, as depicted in Fig. $2 \mathrm{~g}$, when a water droplet adhered on a needle was moved downward and compressed to make contact with the SSCM, it could easily detach from the surface by pulling the needle upwards. These results demonstrated that the as-prepared SSCM was characterized by excellent water repellence, low water adhesion and high oil affinity.

\subsection{Surface morphological analysis}

To explore the mechanism of superhydrophobicity and superoleopholicity induced by dodecyl mercaptan functionalization, surface morphology and chemistry of the meshes were characterized and analyzed. Firstly, the
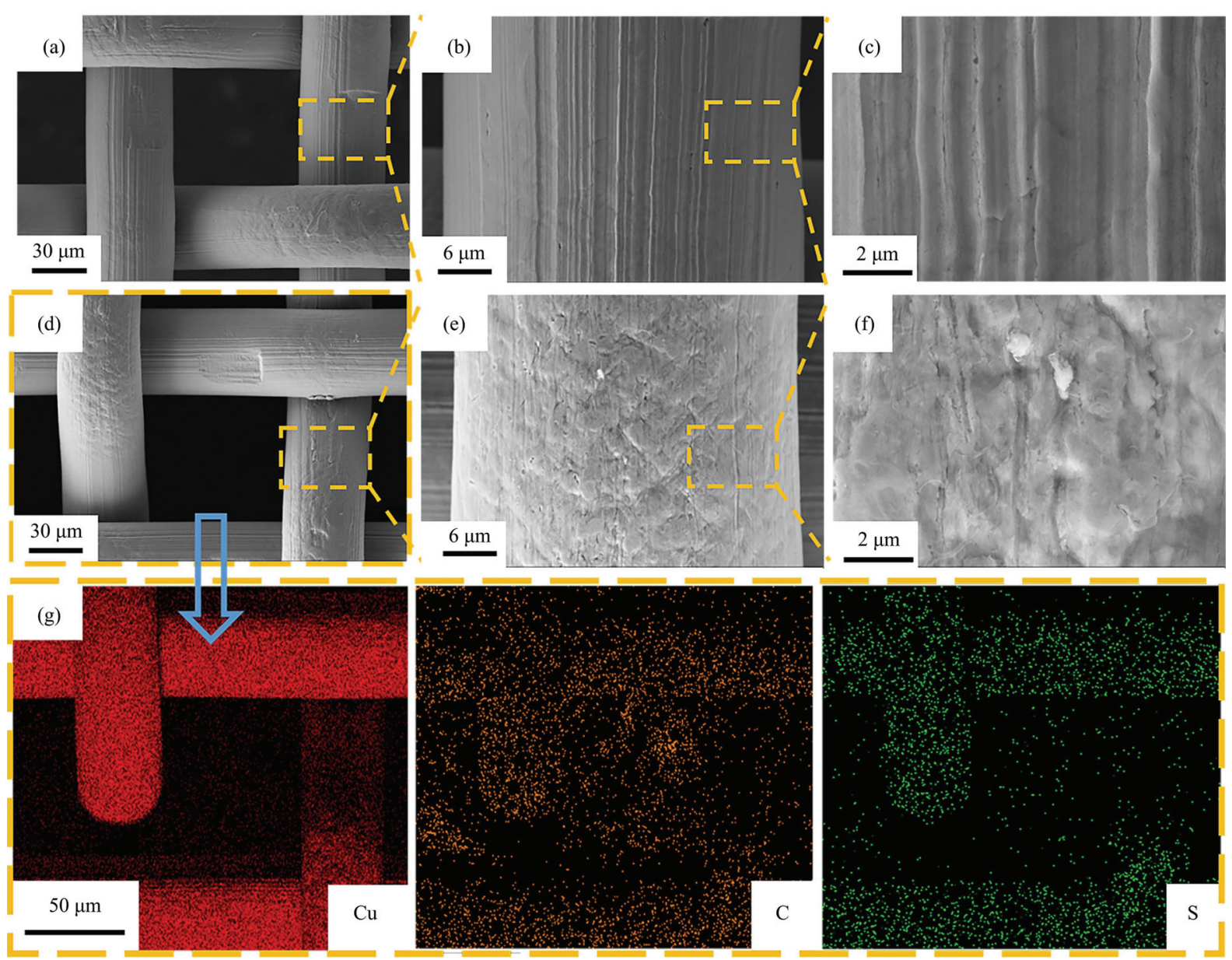

Fig. 3 (a-c) SEM images of the original CM; (d-f) SEM images of the SSCM; (g) EDS elemental mapping (Cu, C, and S) of the SSCM. 
surface morphologies of the pristine CM and the SSCM were recorded by SEM and shown in Figs. 3a - 3f. The original CM was composed of pores with size of $70 \mu \mathrm{m}$ and copper fibers with diameter of $50 \mu \mathrm{m}$ (Fig. 3a). The pristine fibers were relatively smooth and only some scratch-like structures that probably formed during manufacturing of the mesh existed (Figs. $3 b$ and 3c). After being functionalized by dodecyl mercaptan, the average size of the fibers and pores changed little, but some irregular submicron and nano scale trenches and humps appeared on the fibers (Figs. $3 d-3 f$ ). EDS elemental mapping analysis shown in Fig. $3 \mathrm{~g}$ indicated that $\mathrm{C}$ and $\mathrm{S}$ originated from the dodecyl mercaptan molecules (Fig. 1) were uniformly distributed on the fibers of the SSCM, demonstrating successful self-assembly of the dodecyl mercaptan molecules via Eq. (1).

\subsection{XPS analysis}

Additionally, the detailed chemical composition of the pristine CM and SSCM were recorded by XPS and depicted in Fig. 4. Compared with the original CM, dodecyl mercaptan functionalization resulted in a decrease of the relative element content of $\mathrm{Cu}$ (from 63.57 at.\% to 13.43 at.\%) and an increase of C (from 15.35 at.\% to 72.89 at.\%). More importantly, a S 2p peak could be clearly observed on the XPS spectrum of the SSCM (Fig. 4a), and the relative element content of S $2 p$ was 3.44 at.\%. Fig. $4 \mathrm{~b}$ shows the high-resolution S $2 p$ peak fitting results of the SSCM surface. The S $2 p$ was deconvoluted into four components: the peaks centered at $162.3 \mathrm{eV}$ and $163.0 \mathrm{eV}$ were respectively assigned to $\mathrm{S}-\mathrm{C}(2 \mathrm{p} 3 / 2)$ bonds and S-C (2p1/2), and the components at $163.7 \mathrm{eV}$ and $164.7 \mathrm{eV}$ were attributed to $\mathrm{S}-\mathrm{Cu}$ $(2 \mathrm{p} 3 / 2)$ and $\mathrm{S}-\mathrm{Cu}(2 \mathrm{p} 1 / 2)$ groups, respectively ${ }^{[47]}$. Moreover, the high-resolution $\mathrm{C} 1 \mathrm{~s}$ peaks of the original $\mathrm{CM}$ and SSCM were also fitted, and the results were shown in Figs. 4c and 4d. The high-resolution $\mathrm{C} 1 \mathrm{~s}$ peak of original $\mathrm{CM}$ can be fitted to three components at

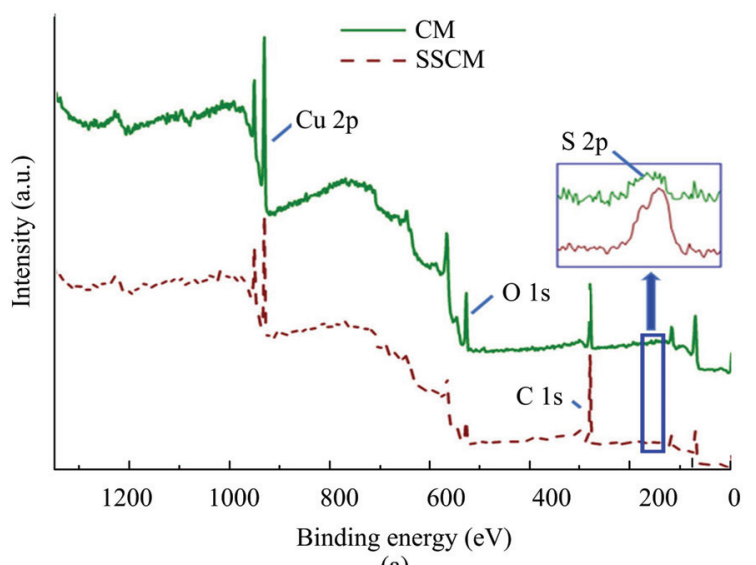

(a)

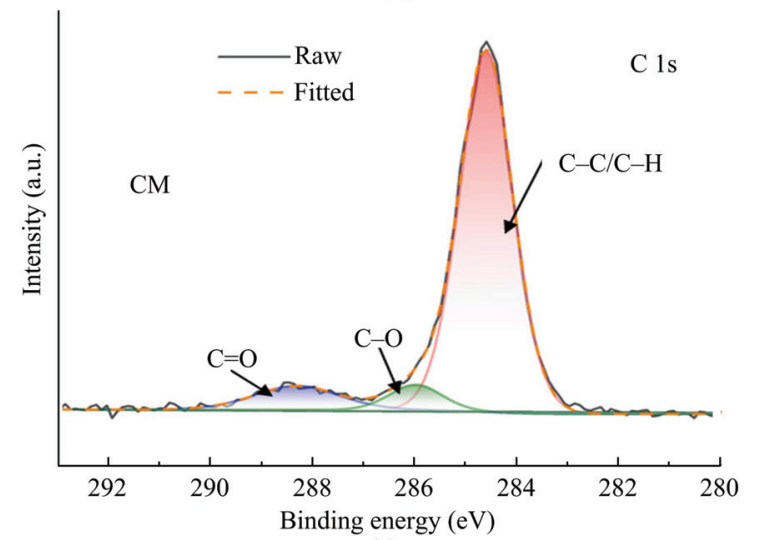

(c)

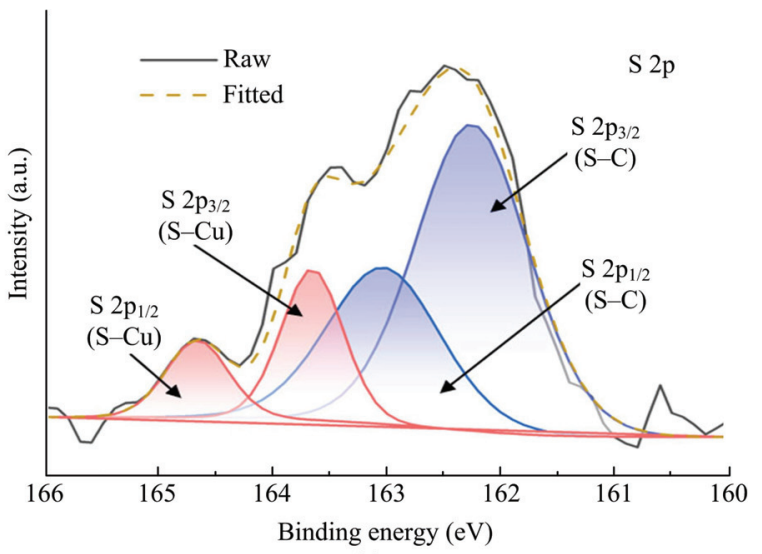

(b)

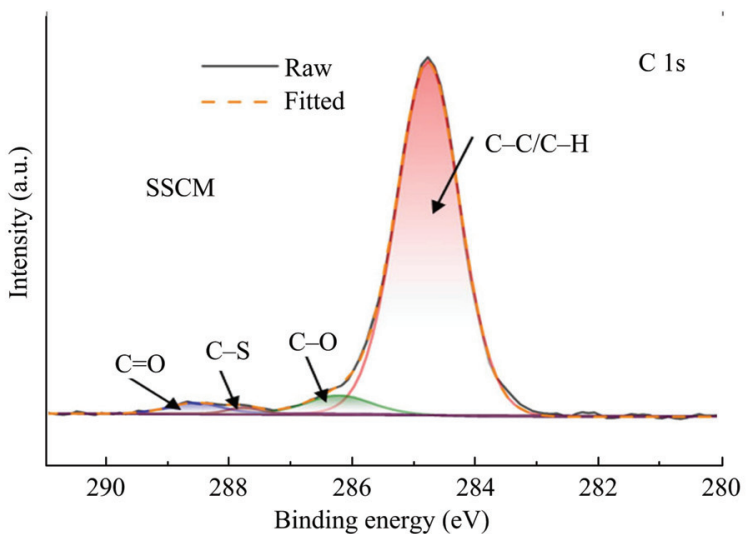

(d)

Fig. 4 (a) XPS spectra of the original CM and SSCM; (b) peak-fitted high-resolution S 2p spectra of the SSCM; (c, d) peak-fitted high-resolution C 1s spectra of the original CM and SSCM. 
$284.80 \mathrm{eV}, 286.3 \mathrm{eV}$ and $288.5 \mathrm{eV}$, corresponding to $\mathrm{C}-\mathrm{C} / \mathrm{C}-\mathrm{H}, \mathrm{C}-\mathrm{O}$ and $\mathrm{C}=\mathrm{O}$ groups, respectively ${ }^{[48]}$ (Fig. $4 \mathrm{c}$ ). By contrast, in addition to these three peaks, a new $\mathrm{C}-\mathrm{S}$ peak could be found at $287.8 \mathrm{eV}$ in the fitted $\mathrm{C} 1 \mathrm{~s}$ peak of SSCM (Fig. 4d). These results all demonstrated the formation of a self-assembled molecular layer on the surface of the mesh during the immersion in dodecyl mercaptan, which lowered the surface energy of the mesh due to the long $\mathrm{C}-\mathrm{C} / \mathrm{C}-\mathrm{H}$ chains of dodecyl mercaptan molecules. The roughened surface morphology and low surface energy met the requirements of lotus-leaf inspired superhydrophobic surfaces, and thereby enabled the functionalized mesh to be super water repellent.

\subsection{Effect of the processing time on wettability}

Fig. 5a shows the influence of mesh number on wettability of the functionalized CM. When the mesh number was 100 , the WCA was only $135.2^{\circ}$, while the WCAs became larger than $150^{\circ}$ when the mesh number was 200, 300 and 400. However, previous works demonstrated that when the mesh number increased, the flux of oil-water separation decreased ${ }^{[49,50]}$. Therefore, the $\mathrm{CM}$ with mesh number of 200 was used to conduct oil-water separation test in this paper.

Then the influence of immersing time on wettability of the functionalized $\mathrm{CM}$ was examined, and the WCAs and Water Sliding Angles (WSAs) under different immersing times were illustrated in Fig. 5b. When the original $\mathrm{CM}$ was immersed in the solution for $30 \mathrm{~min}$, the WCA increased to $108.9^{\circ}$, while the water droplet remained sticky on the mesh, which was probably due to the slight change of the mesh morphology (Fig. 5c). As the immersing time increased to $90 \mathrm{~min}$, irregular micro-nano structures formed on the $\mathrm{CM}$ surface (Fig. 5d), making the WCA increase to $142.3^{\circ}$ and the WSA decrease to $78.5^{\circ}$. When the immersing time was extended to $120 \mathrm{~min}$, the surface of the CM was further roughened (Fig. 5e), and the $\mathrm{CM}$ obtained super water repellence with a WCA of $153.7^{\circ}$ and a WSA of $21.8^{\circ}$. Further increase of the immersing time had little effect on the WCA and WSA of the mesh. Notably, the CM showed superoleophilicity for all the dodecyl mercaptan functionalized CM, therefore the SSCM immersed for
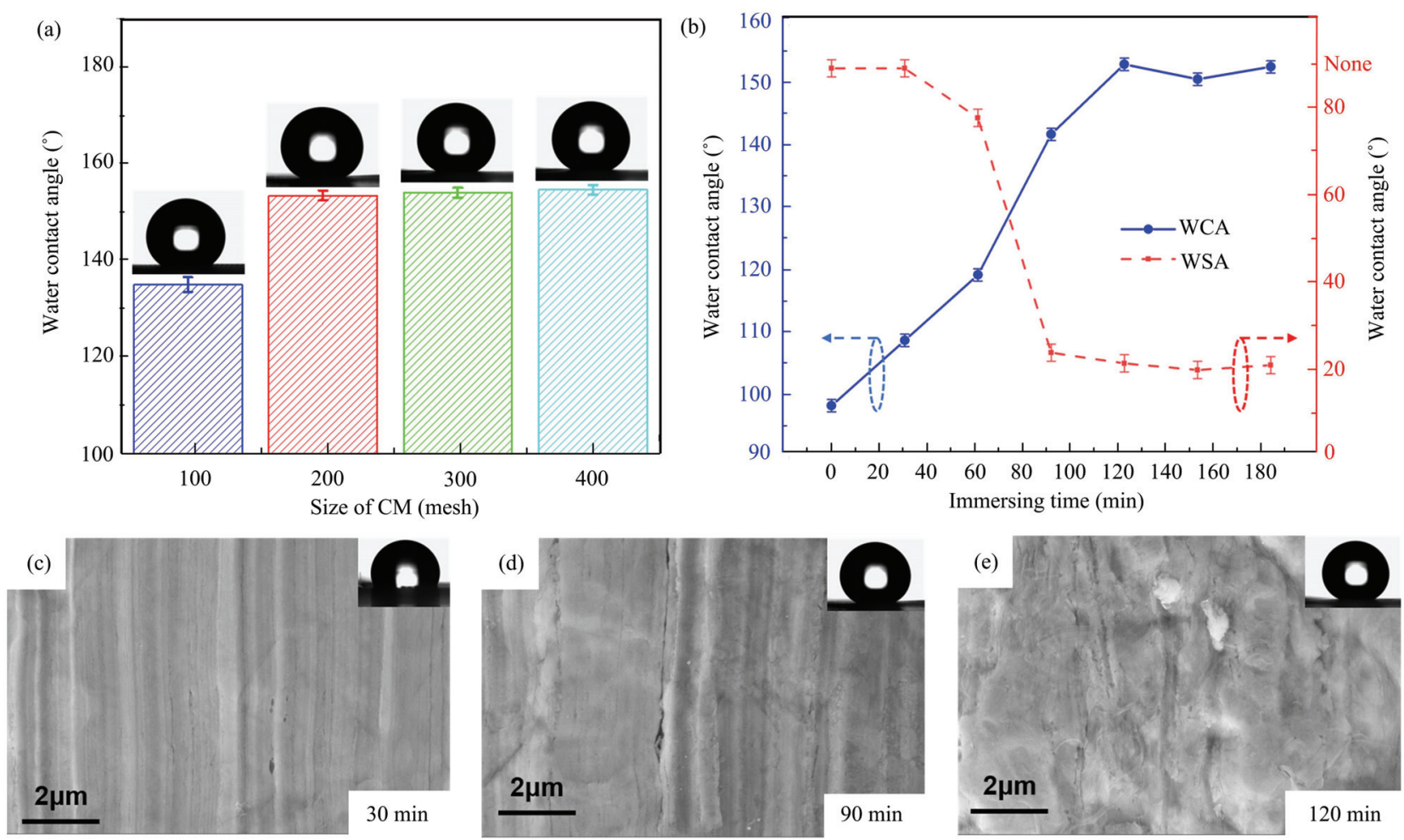

Fig. 5 (a) Influence of the size on the WCA; (b) influence of the immersing time in dodecyl mercaptan ethanol solution on the WCA and WSA of the CM; (c-e) SEM images of the CM under different immersing time, and the insert pictures shows the corresponding water droplet on the surfaces. 
120 min was employed for subsequent oil-water separation.

\subsection{Oil-water separation}

Firstly, we examined the intrusion pressure of the oil-wetted SSCM, which represented the maximum height of water column that could be supported biny the SSCM. The intrusion pressure can be calculated using the equation $\Delta p=\rho g h_{\max }$, where $\Delta p$ was the intrusion pressure, $\rho$ was the density of water, g was the gravitational acceleration, $h_{\max }$ was the maximum height of water column. The maximum heights of water column for oil-prewetted SSCM were measured to be $>11.7 \mathrm{~cm}$, corresponding to the intrusion pressures of $>1.15 \mathrm{kPa}$ (see Fig. S1). This indicated that the SSCM had a good water supporting capacity when it was wetted by oils. Gravity-driven oil-water separation is shown in Fig. 6 and video S1. The SSCM was fixed between two glass tubes by clamps, and then mounted on an iron support. The glass tube was tilted at an angle of $45^{\circ}$ so that it could separate mixtures containing both light oil whose density was smaller than water and heavy oil whose density was larger than water (Fig. 6a). For heavy oils like dichloromethane, when the oil-water mixture was poured into the upper glass tube, water was blocked due to the superhydrophobicity of the SSCM, while dichloromethane could sink to the bottom of the water layer and contact with the SSCM, and then oil passed through the SSCM easily due to its superoleophilicity, leading to the separation of heavy oil-water mixture, and no residual water was observed in the separated oil (Fig.
$6 b)$. When the mixture of water and light oil (e.g., hexadecane, hexane, octane and peanut oil) was poured into the tube, water was stopped by the inclined SSCM and formed a water layer that covered part of the mesh. The oil floated on water surface could contact with the uncovered region of the mesh and flow through the SSCM (Fig. 6a), and finally the oil-water mixture was separated. Figs. $6 \mathrm{c}$ and $6 \mathrm{~d}$ show the separation of water-peanut oil mixture and water-hexane mixture, respectively, demonstrating effective separation of the light oil-water mixtures.

Separation efficiency is an important index to evaluate the oil-water separation capacity of the prepared SSCM, which was measured and shown in Fig. 7a. It could be seen that the separation efficiency of the SSCM was up to $99.2 \%$ for dichloromethane-water mixture, and above $97.1 \%$ for other testing oil-water mixture, and the peanut oil-water mixture was found to be separated with the lowest separation efficiency due to the relatively high viscosity of peanut oil which resulted in some residue on the glass tube wall. Oil flux is also important for the evaluation of the oil-water separation property of the SSCM, which was calculated and shown in Fig. 7b. Peanut oil-water mixture showed an oil flux of $3800 \mathrm{~L} \cdot \mathrm{m}^{-2} \cdot \mathrm{h}^{-1}$ due to its high viscosity, while other oil-water mixtures had oil flux larger than $14000 \mathrm{~L} \cdot \mathrm{m}^{-2} \cdot \mathrm{h}^{-1}$.

In actual separation of oily wastewater, the aqueous phases are always complex, such as high temperature and corrosive solutions, therefore it is important to test the oil-water separation property of the prepared SSCM

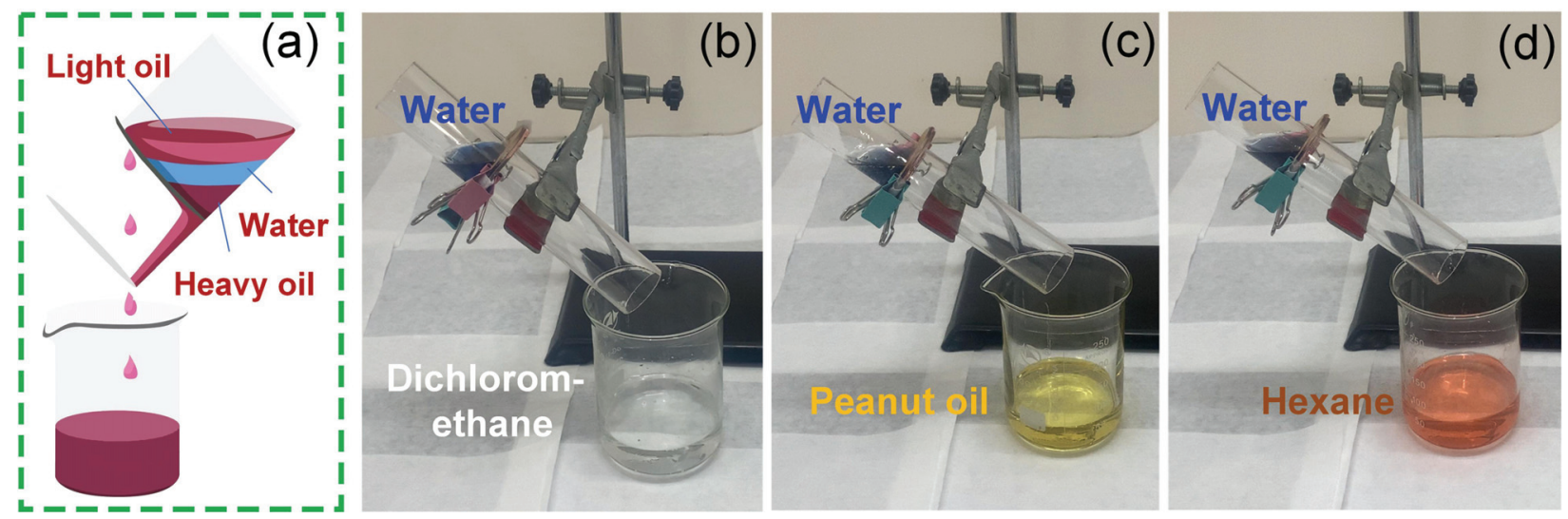

Fig. 6 (a) Schematic diagram of gravity driven oil-water separation by the SSCM; (b-d) digital images of the separated water and various oils. 


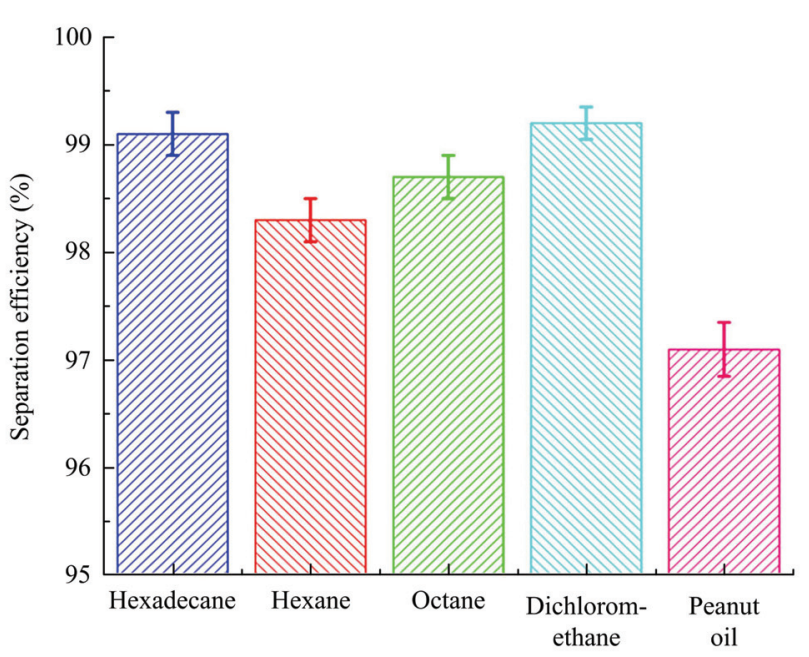

(a)

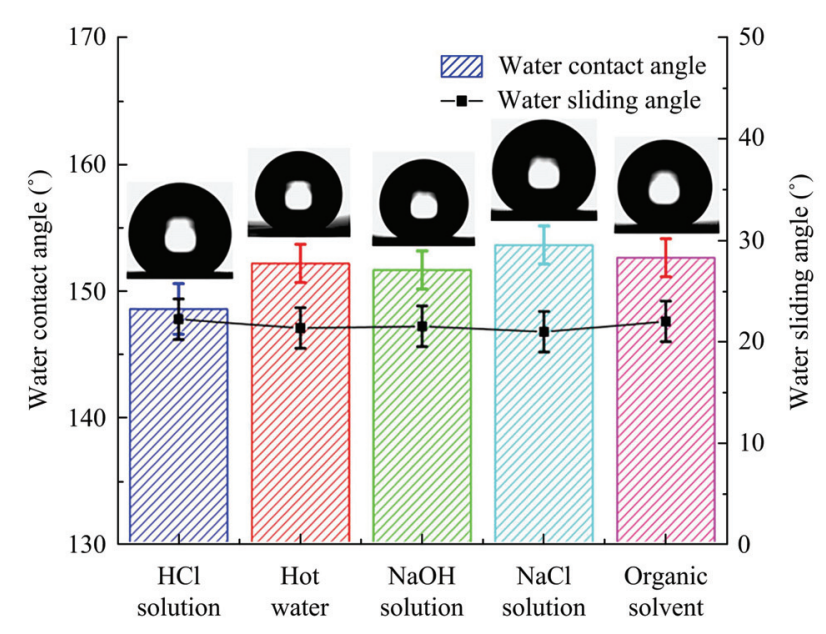

(c)

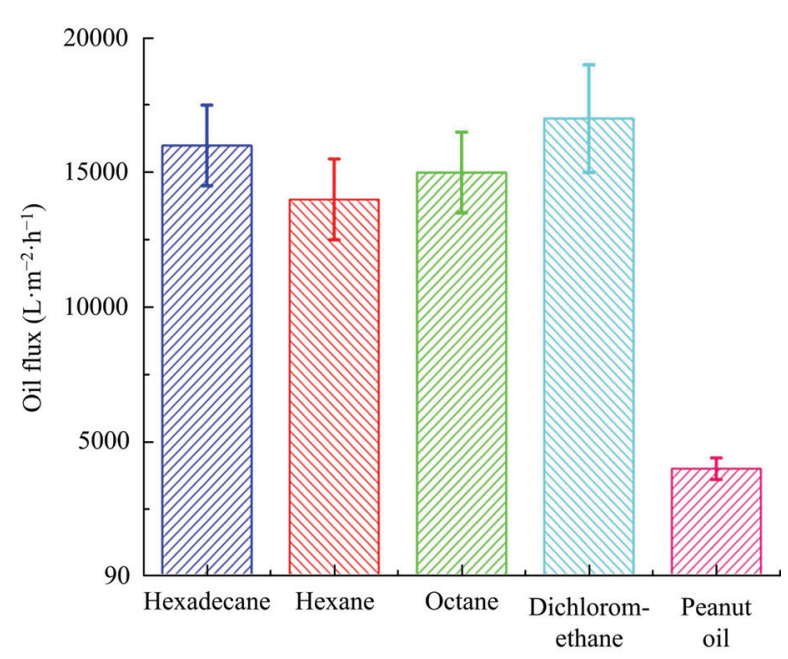

(b)

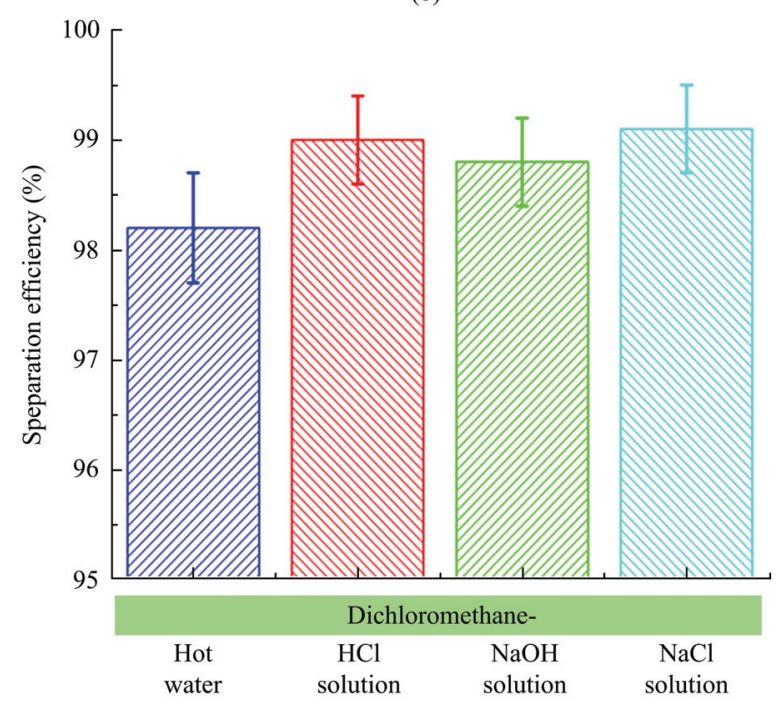

(d)

Fig. 7 (a) Separation efficiency of different oil-water mixtures; (b) oil flux of different oil-water mixtures; (c) WCAs and WSAs of the SSCM after being immersed in hot water $\left(80{ }^{\circ} \mathrm{C}\right), \mathrm{HCl}\left(1 \mathrm{~mol} \cdot \mathrm{L}^{-1}\right), \mathrm{NaOH}\left(1 \mathrm{~mol} \cdot \mathrm{L}^{-1}\right), \mathrm{NaCl}(20 \mathrm{wt} \%)$, and organic solvent (acetone) for $12 \mathrm{~h}$; (d) separation efficiency of the SSCM for the mixtures of dichloromethane and different aqueous solutions.

under complex conditions. Firstly, we tested the stability of water repellence of the mesh after being immersed in complex solutions for $12 \mathrm{~h}$, and the employed solutions included hot water $\left(80{ }^{\circ} \mathrm{C}\right), \mathrm{HCl}\left(1 \mathrm{~mol} \cdot \mathrm{L}^{-1}\right), \mathrm{NaOH}$ $\left(1 \mathrm{~mol} \cdot \mathrm{L}^{-1}\right), \mathrm{NaCl}(20 \mathrm{wt} \%)$, and organic solvent (acetone). As shown in Fig. 7c, the water repellence of the SSCM immersed in these solutions deteriorated little, and the WCAs were all around $150^{\circ}$, and the WSAs remained about $21^{\circ}$, showing durable superhydrophobicity in these complex environments. Then the oil-water separation property of the solution-immersed SSCM was conducted (see Fig. S2 and video S2), and the separation efficiencies of dichloromethane-based mixtures are shown in Fig. 7d. It could be easily ob- served that the dichloromethane passed through the SSCM quickly while the water was blocked, and the separation efficiency of these oil-water mixtures were all above $98 \%$. This indicated that the dodecyl mercaptan functionalized SSCM possessed excellent heat and corrosion resistance and could be used for oil-water separation in harsh environments.

Reusability of the functionalized mesh used for oil-water separation was another important issue for practical application. To investigate the reusability of the SSCM in oil-water separation process, the WCA and separation efficiency of the mesh under different separation cycles were investigated by using hexadecane-water mixture as an example, and the results were 


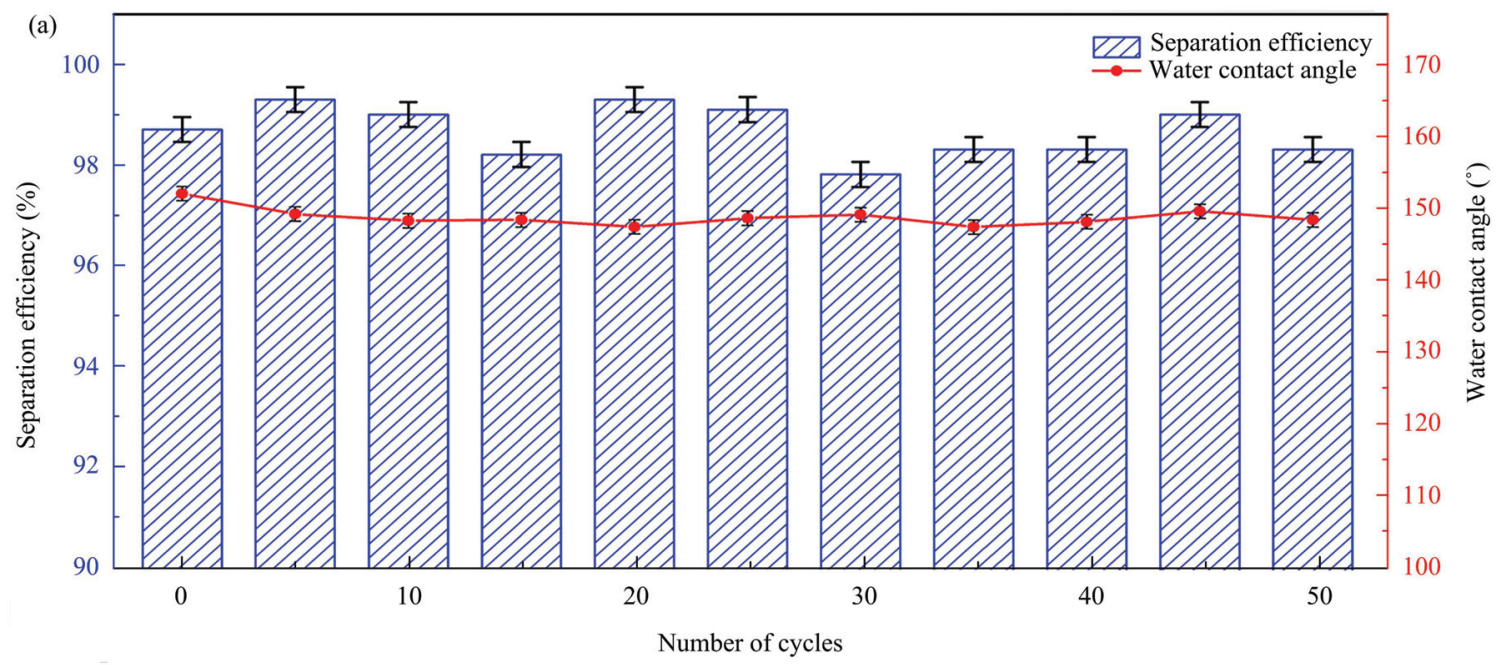

(b)

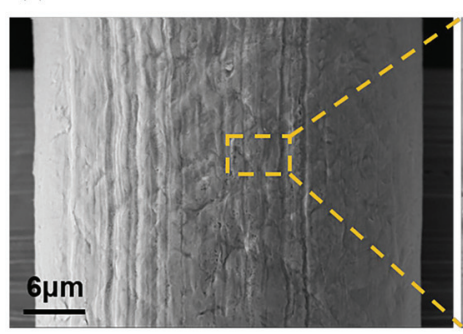

(c)

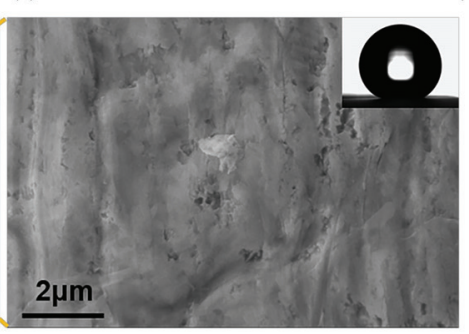

(d)

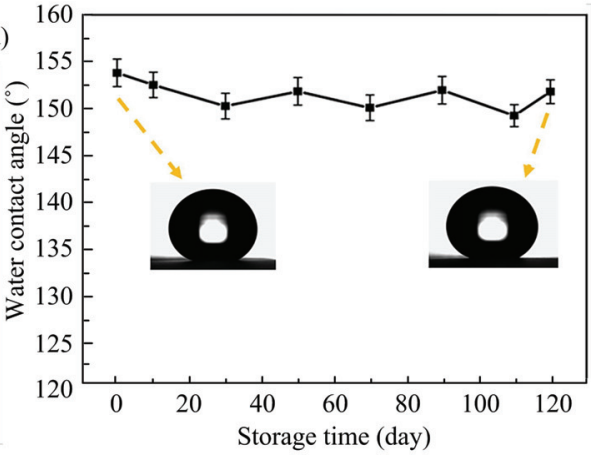

Fig. 8 (a) Variation of the separation efficiency and the WCA during different separation cycles of cetane-water mixture; (b, c) SEM images and WCA profile of the SSCM after 50 cycles of cetane-water separation; (d) change of WCA of the SSCM with the storage time in open air.

depicted in Fig. 8a. During 50 cycles of the oil-water separation, the separation efficiency maintained above $98 \%$ and the WCA retained at about $150^{\circ}$, demonstrating excellent reusability of the SSCM in terms of multiple oil-water separation. In addition, the SEM images of the SSCM after 50 cycles of the oil-water separation were shown in Figs. 8b and 8c. It could be seen that the surface morphology of the SSCM was not obviously damaged during repetitive oil-water separations, which enabled the ability to retain its water repellence and separation capacity. Moreover, Fig. $8 \mathrm{~d}$ shows the stability of water repellence of the SSCM in terms of storage in open air. It could be found that the WCA remained above $150^{\circ}$ even after being stored in air for 120 days, indicating long-term stable superhydrophobicity of the prepared SSCM in air condition.

\subsection{Mechanical durability}

Mechanical robustness of superhydrophobic sur- faces play a very important role in their practical applications. Here we employed sandpaper abrasion testing to evaluate the mechanical durability of the SSCM. As shown in the illustration in Fig. 9a, the SSCM was bonded to a glass slide and placed them face-down to a 1000 grit $\mathrm{SiC}$ sandpaper, making direct contact between the SSCM and sandpaper. Then a $50 \mathrm{~g}$ weight was placed on the slide, and the sample was moved for $10 \mathrm{~cm}$ along the horizontal direction and then moved back in the opposite direction, which was defined as one abrasion cycle. The WCA of the SSCM was measured after each abrasion cycle, and the results were shown in Fig. 9a. It could be seen that the WCA gradually decreased as the abrasion cycle increased, when the sample was abraded for 4 cycles the WCA tended to be $150^{\circ}$, and after 10 abrasion cycles the WCA decreased to about $140^{\circ}$. SEM images (Fig. 9b) showed that after 10 cycles abrasion, some micro/nano structures of the mesh fibers were damaged. Subsequently, these sandpaper abraded 

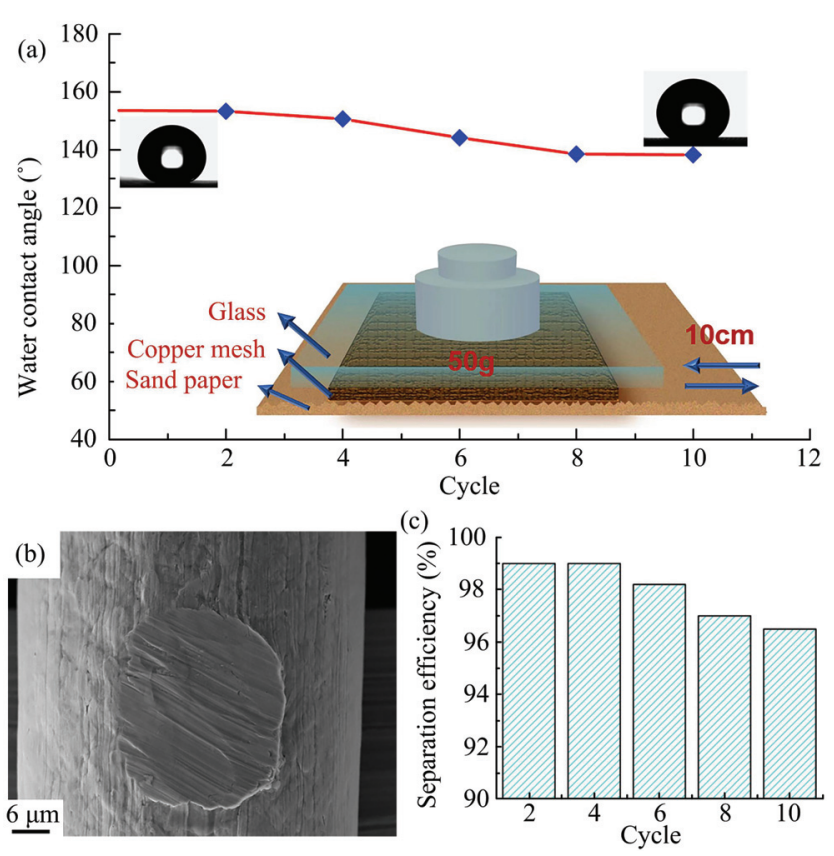

Fig. 9 (a) Variation of the WCA of the SSCM under different sandpaper abrasion cycles (the insert illustration shows the diagram of the abrasion testing); (b) SEM images of the SSCM after 10 cycles of abrasion; (c) separation efficiency of dichloromethane-water mixture during 10 cycles of abrasion.

SSCMs were employed to separate dichloromethane-water mixture, and the separation efficiency was calculated and presented in Fig. 9c. It showed that the separation efficiency changed little after 4 cycles abrasions, and though the water repellence decreased slightly after 10 cycles of abrasion, the separation efficiency retained higher than $96 \%$.

\section{Conclusion}

In summary, SSCM was successfully fabricated using a simple one-step dodecyl mercaptan functionalization. The SSCM showed excellent water repellence and oil affinity (the WCA and OCA were $153.7^{\circ}$ and $0^{\circ}$, respectively), which imparted the SSCM with remarkable oil-water separation capacity. The separation efficiency and oil flux for hexadecane-water mixture were $>$ $99 \%$ and $16000 \mathrm{~L} \cdot \mathrm{m}^{-2} \cdot \mathrm{h}^{-1}$, respectively. The SSCM could be easily reused and the separation efficiency retained $>98 \%$ even after 50 separation cycles. The functionalized SSCM could maintain excellent water repellence even after being immersed in hot water $\left(80{ }^{\circ} \mathrm{C}\right), \mathrm{HCl}\left(1 \mathrm{~mol} \cdot \mathrm{L}^{-1}\right), \mathrm{NaOH}\left(1 \mathrm{~mol} \cdot \mathrm{L}^{-1}\right), \mathrm{NaCl}$ (20 wt $\%$ ) and organic solvent for $12 \mathrm{~h}$, enabling realizable oil-water separation under these harsh conditions.
Additionally, the SSCM could maintain its water repellence and oil-water separation ability even after $10 \mathrm{cy}$ cles sandpaper abrasions. This one-step dodecyl mercaptan immersion could be a simple method to functionalize $\mathrm{CM}$ with robust water repellence and oily wastewater treatment ability.

\section{Acknowledgment}

This paper was financially supported by National Postdoctoral Program for Innovative Talents (No. BX20190233), China Postdoctoral Science Foundation (No. 2019M661012), Tianjin Natural Science Foundation (No. 19JCQNJC03900) and Research Development Foundation of Tianjin University of Technology and Education (No. KYQD202013).

* All supplementary materials are available at https://doi.org/10.1007/s42235-021-0062-7.

Open Access This article is licensed under a Creative Commons Attribution 4.0 International License, which permits use, sharing, adaptation, distribution and reproduction in any medium or format, as long as you give appropriate credit to the original author(s) and the source, provide a link to the Creative Commons licence, and indicate if changes were made.

The images or other third party material in this article are included in the article's Creative Commons licence, unless indicated otherwise in a credit line to the material. If material is not included in the article's Creative Commons licence and your intended use is not permitted by statutory regulation or exceeds the permitted use, you will need to obtain permission directly from the copyright holder.

To view a copy of this licence, visit http://creativecommons.org/licenses/by/4.0/.

\section{References}

[1] Haney J C, Geiger H J, Short J W. Bird mortality from the Deepwater Horizon oil spill. II. Carcass sampling and exposure probability in the coastal gulf of mexico. Marine Ecology Progress Series, 2014, 513, 239-252.

[2] Hegazy E H, Mehanna A K, Omar M Y, Elkilani H, Hassan A A. In coral reefs damage assessment due to oil pollution in egyptian water. Applied Mechanics and Materials, 2014, 522, 725-728.

[3] Schrope M. Deepwater horizon: A scientist at the centre of 
the spill. Nature News, 2010, 466, 680-684.

[4] Klamerus-Iwan A, Błońska E, Lasota J, Kalandyk A, Waligórski P. Influence of oil contamination on physical and biological properties of forest soil after chainsaw use. Water, Air, \& Soil Pollution, 2015, 226, 1-9.

[5] Mirzakhani E, Nejad F M. Grasses and Rhodococcus erythropolis bacteria for bioremediation of naturally polluted soils with hydrocarbons. Chemical Engineering \& Technology, 2016, 39, 1731-1737.

[6] Brakstad O G, Ribicic D, Winkler A, Netzer R. Biodegradation of dispersed oil in seawater is not inhibited by a commercial oil spill dispersant. Marine Pollution Bulletin, 2018, 129, 555-561.

[7] Kong D P, Yang H B, He X. Impact of wind on in-situ burning behavior of spilled oil on open water. Journal of Loss Prevention in the Process Industries, 2020, 65, 104147.

[8] Farooq U, Taban I C, Daling P S. Study of the oil interaction towards oil spill recovery skimmer material: Effect of the oil weathering and emulsification properties. Marine Pollution Bulletin, 2018, 135, 119-128.

[9] Liu Z A, Wang X Y, Gao M Q, Song J L, Huang L, Liu J, Liu $\mathrm{X}, \mathrm{Xu} \mathrm{W}$, Zhao D Y. Unpowered oil absorption by a wettability sponge based oil skimmer. RSC Advances, 2016, 6, 88001-88009.

[10] Barthlott W, Neinhuis C. Purity of the sacred lotus, or escape from contamination in biological surfaces. Planta, 1997, 202, $1-8$.

[11] Liu M J, Wang S T, Wei Z X, Song Y L, Jiang L. Bioinspired design of a superoleophobic and low adhesive water/solid interface. Advanced Materials, 2009, 21, 665-669.

[12] Zhai L, Berg M C, Cebeci F C, Kim Y S, Milwid J M, Rubner M F, Cohen R E. Patterned superhydrophobic surfaces: Toward a synthetic mimic of the namib desert beetle. Nano Letters, 2006, 6, 1213-1217.

[13] Wang P, Li Z Q, Xie Q, Duan W, Zhang X C, Han H L. A passive anti-icing strategy based on a superhydrophobic mesh with extremely low ice adhesion strength. Journal of Bionic Engineering, 2021, 18, 55-64.

[14] Archer R J, Becher-Nienhaus B, Dunderdale G J, Hozumi A. Recent progress and future directions of multifunctional (super)wetting smooth/structured surfaces and coatings. Advanced Functional Materials, 2020, 30, 1907772.

[15] Lu Y, Sathasivam S, Song J L, R. C C, Carmalt C J, Parkin I P. Robust self-cleaning surfaces that function when exposed to either air or oil. Science, 2015, 347, 1132-1135.

[16] Long M Y, Ma Y, Yang C, Zhang R N, Jiang Z Y. Superwetting membranes: From controllable constructions to ef- ficient separations. Journal of Materials Chemistry A, 2021, 9, 1395-1417.

[17] Xiao Z, Zhang L Q, Zhang W W, Yu X Q, Zhang Y F. Thermal stability of typical superhydrophobic surfaces. Journal of Bionic Engineering, 2018, 15, 1025-1034.

[18] Akbari R, Godeau G, Mohammadizadeh M, Guittard F, Darmanin T. Wetting transition from hydrophilic to superhydrophobic over dendrite copper leaves grown on steel meshes. Journal of Bionic Engineering, 2019, 16, 719-729.

[19] Yang C J, Chao J Q, Zhang J C, Zhang Z T, Liu X, Tian Y L, Zhang D W, Chen F Z. Functionalized cfrp surface with water-repellence, self-cleaning and anti-icing properties. Colloids and Surfaces A: Physicochemical and Engineering Aspects, 2020, 586, 124278.

[20] Chen G Y, Wang Y N, Wang Y J, Xiao H Z, Huang X, Shi B Collagen fibers with tuned wetting properties for dual separation of oil-in-water and water-in-oil emulsion. Journal of Materials Chemistry A, 2020, 8, 24388-24392.

[21] Lu Y, Sathasivam S, Song J L, Chen F Z, Xu W J, Carmalt C J, Parkin I P. Creating superhydrophobic mild steel surfaces for water proofing and oil-water separation. Journal of Materials Chemistry A, 2014, 2, 11628-11634.

[22] khalilifard M, Javadian S. Magnetic superhydrophobic polyurethane sponge loaded with $\mathrm{Fe}_{3} \mathrm{O}_{4} @$ oleic acid@graphene oxide as high performance adsorbent oil from water. Chemical Engineering Journal, 2021, 408, 127369.

[23] Zhang J X, Zhu L N, Zhao S Y, Wang D H, Guo Z G. A robust and repairable copper-based superhydrophobic microfiltration membrane for high-efficiency water-in-oil emulsion separation. Separation and Purification Technology, 2021, 256, 117751.

[24] Yang S D, Chen L, Liu S, Hou W J, Zhu J, Zhang Q, Zhao P. Robust bifunctional compressed carbon foam for highly effective oil/water emulsion separation. ACS Applied Materials \& Interfaces, 2020, 12, 44952-44960.

[25] Xiong Z, He Z J, Mahmud S, Yang Y, Zhou L, Hu C, Zhao S F. Simple amphoteric charge strategy to reinforce superhydrophilic polyvinylidene fluoride membrane for highly efficient separation of various surfactant-stabilized oil-in-water emulsions. ACS Applied Materials \& Interfaces, 2020, 12, 47018-47028.

[26] Fu C, Gu L, Zeng Z X, Xue Q J. Simply adjusting the unidirectional liquid transport of scalable janus membranes toward moisture-wicking fabric, rapid demulsification, and fast oil/water separation. ACS Applied Materials \& Interfaces, 2020, 12, 51102-51113.

[27] Kong W T, Pan Y L, Bhushan B, Zhao X. Superhydrophilic 
$\mathrm{Al}_{2} \mathrm{O}_{3}$ particle layer for efficient separation of oil-in-water (o/w) and water-in-oil (w/o) emulsions. Langmuir, 2020, 36, 13285-13291.

[28] Arumugam H, Mohamed Ismail A A, Govindraj L, Muthukaruppan A. Development of bio-based benzoxazines coated melamine foam for oil-water separation. Progress in Organic Coatings, 2021, 153, 106128.

[29] Dula D E, Wang C F, Lin C H, Kuo S W, Chen J K, Tsai H C, Hung $\mathrm{W}$ S, Hu C C, Juin Y L. Preparation of a main-chain-type polybenzoxazine-modified melamine sponge via non-solvent-induced phase inversion for oil absorption and very-high-flux separation of water-in-oil emulsions. Separation and Purification Technology, 2021, 263, 118387.

[30] Xu L, Zang Y, Xiao J J, Wu Y F, Pan Y X, Wu T T, Tang Y S, Cui J, Jia H G, Miao F J. Superhydrophobic conjugated microporous polymer-coated sponges: Synthesis and application for highly efficient oil/water separation and the recovery of palladium ions. Separation and Purification Technology, 2021, 261, 118291.

[31] Yang Y S, Chen X D, Li Y M, Yin Z, Bao M. Construction of a superhydrophobic sodium alginate aerogel for efficient oil absorption and emulsion separation. Langmuir, 2021, 37, 882-893.

[32] Xie X S, Zheng Z Z, Wang X Q, Lee Kaplan D. Low-density silk nanofibrous aerogels: Fabrication and applications in air filtration and oil/water purification. ACS Nano, 2021, 15, 1048-1058.

[33] Koh E, Lee Y T. Preparation of an omniphobic nanofiber membrane by the self-assembly of hydrophobic nanoparticles for membrane distillation. Separation and Purification Technology, 2021, 259, 118134.

[34] Yin X L, Yu S R, Wang L Y, Li H, Xiong W. Design and preparation of superhydrophobic nis nanorods on Ni mesh for oil-water separation. Separation and Purification Technology, 2020, 234, 116126.

[35] Song Y, Liu Y, Zhan B, Kaya C, Stegmaier T, Han Z W, Ren L Q. Fabrication of bioinspired structured superhydrophobic and superoleophilic copper mesh for efficient oil-water separation. Journal of Bionic Engineering, 2017, 14, 497-505.

[36] Tudu B K, Kumar A. Robust and durable superhydrophobic steel and copper meshes for separation of oil-water emulsions. Progress in Organic Coatings, 2019, 133, 316-324.

[37] Asad A, Rastgar M, Sameoto D, Sadrzadeh M. Gravity assisted super high flux microfiltration polyamide-imide membranes for oil/water emulsion separation. Journal of Membrane Science, 2021, 621, 119019.
[38] Liu R R, Chen Q, Cao M Y, Lin J Y, Lin F, Ye W Y, Luis P, Van der Bruggen B, Zhao S F. Robust bio-inspired superhydrophilic and underwater superoleophobic membranes for simultaneously fast water and oil recovery. Journal of Membrane Science, 2021, 623, 119041.

[39] Liu H, Chen X Y, Zheng Y J, Zhang D B, Zhao Y, Wang C F, Pan C F, Liu C T, Shen C Y. Lightweight, superelastic, and hydrophobic polyimide nanofiber/mxene composite aerogel for wearable piezoresistive sensor and oil/water separation applications. Advanced Functional Materials, 2021, 20, 2008006.

[40] Huang L, Zhang L L, Song J L, Wang X Y, Liu H. Superhydrophobic nickel-electroplated carbon fibers for versatile oil/water separation with excellent reusability and high environmental stability. ACS Applied Materials \& Interfaces, 2020, 12, 24390-24402.

[41] Li L Y, Zhu J F, Zeng Z X. New approach for recycling office waste paper: An efficient and recyclable material for oily wastewater treatment. ACS Applied Materials \& Interfaces, 2020, 12, 55894-55902.

[42] Cheng Z J, Du M, Lai H, Zhang N Q, Sun K N. From petal effect to lotus effect: A facile solution immersion process for the fabrication of super-hydrophobic surfaces with controlled adhesion. Nanoscale, 2013, 5, 2776-2783.

[43] Liu J, Wang L, Wang N, Guo F Y, Hou L L, Chen Y E, Liu J $\mathrm{C}$, Zhao Y, Jiang L. A robust $\mathrm{Cu}(\mathrm{OH})_{2}$ nanoneedles mesh with tunable wettability for nonaqueous multiphase liquid separation. Small, 2017, 13, 1600499.

[44] Stephen B A, Lim Y T, Lee H J, San Choi W. Structure-controllable superhydrophobic $\mathrm{Cu}$ meshes for effective separation of oils with different viscosities and aqueous pollutant purification. RSC advances, 2016, 6, 17642-17650.

[45] Gu C D, Tu J P. One-step fabrication of nanostructured Ni film with lotus effect from deep eutectic solvent. Langmuir, 2011, 27, 10132-10140.

[46] Li D G, Yu X J, Dong Y H. The different self-assembled way of $n$ - and $t$-dodecyl mercaptan on the surface of copper. Applied Surface Science, 2007, 253, 4182-4187.

[47] Darlatt E, Muhsin B, Roesch R, Lupulescu C, Roth F, Kolbe M, Gottwald A, Hoppe H, Richter M. Irradiation-induced degradation of PTB7 investigated by valence band and S 2p photoelectron spectroscopy. Nanotechnology, 2016, 27, 324005.

[48] Li X Y, Jiang Y, Jiang Z H, Li Y C, Wen C E, Zhang D M, Lian J S, Zhang Z H. Improvement of corrosion resistance of h59 brass through fabricating superhydrophobic surface 
using laser ablation and heating treatment. Corrosion Science, 2021, 180, 109186.

[49] Zhang F, Zhang W B, Shi Z, Wang D, Jin J, Jiang L. Nanowire-haired inorganic membranes with superhydrophilicity and underwater ultralow adhesive superoleophobicity for high-efficiency oil/water separation. Advanced Materials,
2013, 25, 4192-4198.

[50] Xiao C M, Si L X, Liu Y M, Guan G Q, Wu D H, Wang Z D, Hao X G. Ultrastable coaxial cable-like superhydrophobic mesh with self-adaption effect: Facile synthesis and oil/water separation application. Journal of Materials Chemistry A, 2016, 4, 8080-8090. 